\title{
Feasibility and Usefulness of a Joystick-Guided Robotic Scope Holder (Soloassist) in Laparoscopic Surgery
}

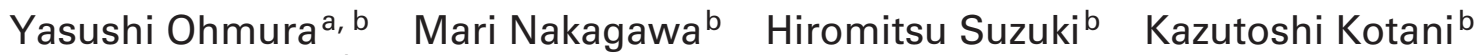 \\ Atsushi Teramoto ${ }^{b}$ \\ a Department of Cancer Treatment Support Center, Okayama City Hospital, Okayama City, Okayama, Japan; \\ ${ }^{b}$ Department of Surgery, Okayama City Hospital, Okayama City, Okayama, Japan
}

\section{Keywords}

Laparoscopic surgery · Robotic scope holder .

Soloassist · Cholecystectomy

\section{Summary}

Introduction: The Soloassist ${ }^{\circledR}$ system is a joystick-guided robotic scope holder. We evaluated the efficacy of Soloassist in laparoscopic surgery. Methods: We investigated operative time, blood loss, set-up time, length of hospital stay, and the number of participating surgeons in laparoscopic cholecystectomy cases before and after the introduction of Soloassist. Furthermore, we evaluated these factors in each group of 20 elective and emergency cholecystectomy cases by single surgeon after matching their background. To evaluate the performance level of operating Soloassist, we divided the operative field into three areas. Then we counted the frequency of energy device activation in initially 10 cases by a single surgical resident and observed its change. Results: The number of participating surgeons was significantly less and postoperative hospital days were fewer in the Soloassist group. There was no significant difference between set-up time and blood loss both in elective and emergency cases. The total number of energy device activations and that in the dangerous area decreased in accordance with the experience. Conclusion: Considering our results and previous reports, the combination use of an ideal active scope holder and a commercially available 3D scope is currently considered the best approach in laparoscopic surgery. In the near future, development of active scope holders might play an important role in laparoscopic surgery.

(c) 2018 The Author(s). Published by S. Karger GmbH, Freiburg

\section{KARGER}

Fax +497614520714 Information@Karger.com www.karger.com

$\begin{array}{ll}\text { (๑) } 2018 \text { The Author(s) } & \text { Karger } \\ \text { Published by S. Karger GmbH, Freiburg } & \text { Open access }\end{array}$

This article is licensed under the Creative Commons AttributionNonCommercial-NoDerivatives 4.0 International License (CC BYNCND 4.0) (http://www.karger.com/Services/OpenAccessLicense).

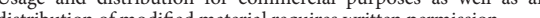

\section{Introduction}

The history of laparoscopic general surgery dates back to the introduction of appendectomy by Semm in 1980 [1] and of cholecystectomy by Mühe in 1985 [2]. Subsequently, laparoscopic surgery was applied to various procedures [3-5]. Over the years, the laparoscopic instruments have been gradually evolved, which contributed to the improvement of quality and diversity of laparoscopic procedures. Among them, advances in energy devices and imaging are remarkable, and the progress made contributes to deepening anatomical knowledge and providing a safer and more stable technique. In recent years, robotic surgery represented by the da Vinci ${ }^{\circledR}$ system (Intuitive Surgical, Inc., Sunnyvale, CA, USA) has attracted attention, and various results have been reported by a limited amount of institutions [6-8]. In contrast, considering both the advantages and high costs of robotic surgery, there are some major problems not to be ignored [9-11].

Scope holders can reduce the number of participants in surgery and provide a stable surgical field without tremors. Initially, scope holders were only invented with the intention to fix the scope [12, 13]; however, robotic scope holders have recently been developed that allow the operator to control the scope without removing the hands from the forceps [14-16]. The Soloassist ${ }^{\circledR}$ system (AKTORmed, Barbing, Germany), a unique robotic scope holder, is a joystickguided endoscope remote control system which enables the surgeon to control the field of view [17]. In the following, we report our experiences with Soloassist for various surgical procedures, and the results of our experimental research to assess its benefits.

\section{Soloassist II ${ }^{\circledR}$ Robotic Camera Control System}

Soloassist II is an endoscope holder with computer-controlled electric motors (fig. 1), which is a newly evolved as well as improved model compared to the previous version. It has six joints: three are 
computer-controlled, one can be adjusted manually, and two act as a gimbal joint following the movement of the main body. The only parts that require sterilization are the universal joint, camera clamp, and joystick, whereas the main body is covered by a dedicated singleuse drape. Soloassist can be easily installed on any part of the side rail of the operation table thanks to the quick-coupling device. After adjusting the 'trocar point' that defines the axis of motion, scope movement can be controlled by the surgeon in a straightforward and intuitive fashion via an ergonomic joystick positioned on the left-hand side of the instrument. While fine movements are adjusted by joystick, dynamic movement can be enabled manually with the unlock bottom. Basically, we attach Soloassist to the operation table rail on the opposite side of the standing position of the operator. In most cases, there is no need to change our customary way of working; however, in order to eliminate interference with the forceps, we have brought forward some ideas for use in cholecystectomy and five-port rectal resection. In cholecystectomy, the port position typically used with the operator's left forceps is shifted to the foot side by approximately $5 \mathrm{~cm}$. Moreover, in five-port rectal resection in the lithotomy position, Soloassist is attached to the upper left position of the patient.

\section{Our Experiences and Experimental Study}

A total of 949 laparoscopic and thoracoscopic procedures with Soloassist were performed in our institution between December 2014 and March 2017. The respective operative procedures are shown in table 1 . We regularly used Soloassist not only for elective surgery but also for emergency surgery during nighttime. In our experience, $36 \%$ of cholecystectomy, $95 \%$ of appendectomy and $100 \%$ of cases for upper gastrointestinal perforation were performed in emergency situations. Based on these cases, we retrospectively conducted two experimental studies regarding the cholecystectomy.

Firstly, we investigated operative duration, amount of bleeding, length of hospital stay after surgery, and the number of participating surgeons in laparoscopic cholecystectomy cases before and after the introduction of Soloassist (Study 1). For the purpose of evaluating whether the set-up time of Soloassist affected the result objectively, the time from room entry to initial skin incision was calculated as 'set-up time' which also included the time required for anesthetic administration. As this is a retrospective study and as it can be considered that the different backgrounds of these cases might affect the outcome, we conducted a similar study in 80 cases (elective surgery: 40 cases, emergency surgery: 40 cases) operated on by a single surgeon (Y.O.) after matching the background. We evaluated the patients' characteristics and perioperative results in each group of 20 elective cholecystectomy cases (Study 1A) as well as emergency cases (Study 1B). The group of cases in which a human assistant operated the laparoscope before introducing Soloassist was named the HA group, and the group using Soloassist was called the SA group.

Secondly, with the aim of evaluating the performance level of operating Soloassist, we created two ellipses which were 50 and $80 \%$ the length and width of the monitor to divide the operative field into three areas (fig. 2). Thereupon, we used areas to define

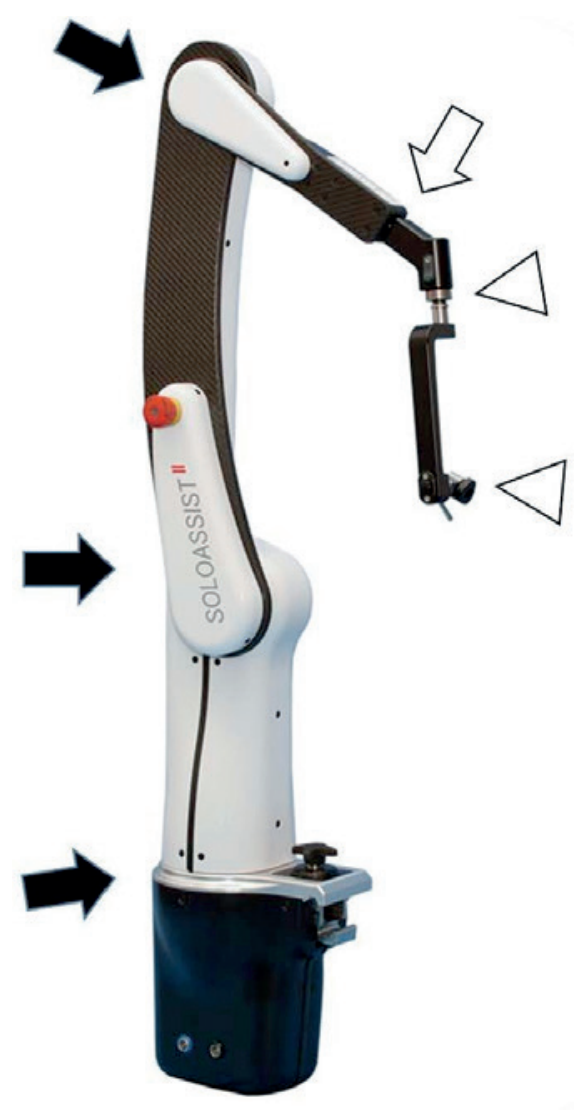

Fig. 1. Soloassist $\mathrm{II}^{\circledR}$ has six joints: three are computer-controlled (black arrows), one can be adjusted manually (white arrow), and two act as a gimbal joint following the movement of the main body (white arrow heads).

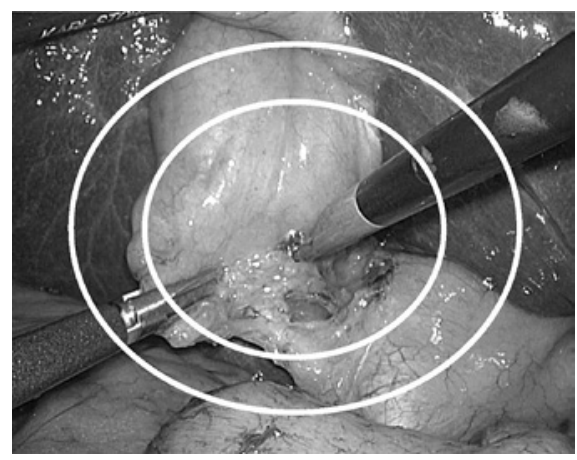

Fig. 2. Surgical map evaluating eligibility of operative field: The operative field was divided into three areas by two ellipses of 50 and $80 \%$ in length and width of the monitor, and they were defined as the safe zone, boundary zone, and dangerous zone as the locations inside of $50 \%$, between 50 and $80 \%$, and outside of $80 \%$, respectively.

the safe zone, boundary zone, and dangerous zone as the locations inside of $50 \%$, between 50 and $80 \%$, and outside of $80 \%$, respectively. Then we counted the number of times the energy device was activated according to the defined fields in an initial study of 10 cases by a single surgical resident. We estimated whether there was a change depending on the amount of experience (Study 2).

\section{Statistical Analyses}

Comparisons between the groups were made with the Student's $\mathrm{t}$ test. The Fisher's exact test and Chi-square test were used for comparison of categorical values. A two-sided p-value $<0.05$ was considered to be statistically significant. 
Table 1. Experienced surgical procedures with Soloassist II $(12 / 2014-03 / 2017)^{\mathrm{a}}$

\begin{tabular}{|c|c|c|c|c|}
\hline \multicolumn{2}{|l|}{ Method } & \multicolumn{2}{|l|}{ Location/approach } & \multirow[t]{2}{*}{ Emergency, n (\%) } \\
\hline Type & $\mathrm{n}$ & type & $\mathrm{n}$ & \\
\hline Esophagectomy & 6 & - & - & 0 \\
\hline GERD (Toupet operation) & 3 & - & - & 0 \\
\hline Gastrectomy & 53 & $\mathrm{~L} / \mathrm{DG} / \mathrm{TG}$ & $6 / 33 / 14$ & 0 \\
\hline UGI perforation & 16 & - & - & $16(100)$ \\
\hline Gastrojejunostomy & 6 & - & - & 0 \\
\hline Small intestinal resection & 12 & - & - & 0 \\
\hline Appendectomy & 166 & - & - & $163(98.2)$ \\
\hline Colectomy & 89 & $\mathrm{C} / \mathrm{A} / \mathrm{T} / \mathrm{D} / \mathrm{S}$ & $9 / 31 / 10 / 3 / 36$ & 0 \\
\hline Rectal resection & 46 & $\mathrm{Rs} / \mathrm{Ra} / \mathrm{Rb}$ & $21 / 17 / 8$ & 0 \\
\hline Subtotal colectomy & 2 & - & - & 0 \\
\hline Rectal prolapse (Wells operation) & 9 & - & - & 0 \\
\hline Cholecystectomy & 273 & 4 ports / single port & $252 / 21$ & $101(37.0)$ \\
\hline Hepatectomy & 12 & Seg. / Par. & $2 / 10$ & 0 \\
\hline Pancreatectomy & 3 & - & - & 0 \\
\hline Splenectomy & 8 & - & - & 0 \\
\hline Ventral hernioplasty & 6 & - & - & 0 \\
\hline Hernioplasty & 98 & unilateral / bilateral & $85 / 13$ & 0 \\
\hline Adrenectomy & 1 & - & - & 0 \\
\hline Infected urchus & 3 & - & - & 0 \\
\hline Nephrectomy & 26 & - & - & 0 \\
\hline Prostatectomy & 20 & - & - & 0 \\
\hline Pulmonary resection & 63 & Lob. / Seg. / Par. & $17 / 6 / 40$ & 0 \\
\hline Others & 28 & - & - & $1(3.6)$ \\
\hline Total & 949 & & & $281(29.6)$ \\
\hline
\end{tabular}

aTumor location is classified according to the Japanese Classification of Colorectal Carcinoma. GERD = Gastroesophageal reflux disease; UGI perforation = upper gastrointestinal perforation; $\mathrm{L}=$ local resection; $\mathrm{DG}$ = distal gastrectomy; $\mathrm{TG}=$ total gastrectomy; Seg. = segmental resection; Par. = partial resection; Lob. = lobectomy; $\mathrm{C}=$ cecum; $\mathrm{A}=$ ascending colon; $\mathrm{T}=$ transverse colon; $\mathrm{D}=$ descending colon; $\mathrm{S}=$ sigmoid colon; $\mathrm{Rs}=$ rectosigmoid colon; $\mathrm{Ra}=$ upper rectum; $\mathrm{Rb}=$ lower rectum.

\section{Results}

In all 949 procedures with Soloassist, including emergency cases, there was no conversion to human assistant. Since its introduction, we have not experienced any mechanical troubles. There were only a few occasions where Soloassist did not respond to the joystick but could be normally used after replacing it with a new one. As the main body of Soloassist was wrapped with a drape and only a few of the parts required an autoclave, it was possible to use Soloassist in up to 5 cases of surgery per day, e.g. 4 cases of elective surgery and 1 case of emergency.

\section{Study 1}

A total of 490 cholecystectomies was performed between April 2011 and March 2017. Among them, we conducted a retrospective study in 382 cases of laparoscopic cholecystectomy, excluding the cases of choledocholithotomy and simultaneous multiple organ resection and open cholecystectomy. Single-port cholecystectomy was performed in 29 cases (HA group: 8 cases, SA group: 21 cases). The patients' characteristics and perioperative results are shown in table 2. The number of cases examined was 134 in the HA group and 248 in the SA group. Preoperative clinical information, includ- ing age, sex, body mass index (BMI), and ASA score, was comparable in both groups. The number of participating surgeons was significantly less in the SA group $(2.8 \pm 0.49$ vs. $2.3 \pm 0.50, \mathrm{p}<0.01)$ and the operation time and postoperative length of hospital stay were also shorter $(131.4 \pm 57.8$ vs. $107.2 \pm 47.5 \mathrm{~min}, \mathrm{p}<0.01 ; 9.4 \pm$ 4.2 vs. $6.5 \pm 4.9$ days, $\mathrm{p}=0.04$, respectively). There was no significant difference between set-up time and amount of intraoperative blood loss.

The results of stratified analyses for elective and emergency cases are shown in table 3 and 4, respectively. Both studies demonstrate that the number of surgeons participating in surgery was significantly less in the SA group and the operation time was also shorter. Postoperative hospital stay of elective cases was shorter in the SA group. There was no significant difference between set-up time and amount of intraoperative blood loss.

\section{Study $1 A$}

The patients' characteristics and perioperative results in 20 elective laparoscopic cholecystectomy cases before and after introducing Soloassist are shown in table 5. Preoperative clinical information including age, sex, BMI, and ASA score was comparable in both groups. The number of surgeons participating in surgery was 
Table 2. Patients' characteristics and perioperative results in all laparoscopic cholecystectomy cases

Table 3. Patients' characteristics and perioperative results in elective cholecystectomy

\begin{tabular}{|c|c|c|c|c|c|c|c|}
\hline & \multicolumn{3}{|c|}{$\begin{array}{l}\text { Human assistant group } \\
(\mathrm{n}=134)\end{array}$} & \multicolumn{3}{|c|}{$\begin{array}{l}\text { Soloassist group } \\
(\mathrm{n}=248)\end{array}$} & \multirow[t]{2}{*}{$\mathrm{p}$} \\
\hline & mean & SD & range & mean & SD & range & \\
\hline Age, years & 64.1 & 16.7 & $27-93$ & 64.7 & 15.9 & $16-95$ & 0.30 \\
\hline Sex, male/female & & $62 / 72$ & & & $125 / 123$ & & 0.54 \\
\hline BMI, $\mathrm{kg} / \mathrm{m}^{2}$ & 23.9 & 4.0 & $15.6-34.3$ & 23.6 & 4.0 & $11.4-38.6$ & 0.45 \\
\hline \multicolumn{8}{|l|}{ ASA score } \\
\hline 1 & 29 & & & 59 & & & \multirow{4}{*}{0.54} \\
\hline 2 & 70 & & & 124 & & & \\
\hline 3 & 33 & & & 63 & & & \\
\hline 4 & 2 & & & 2 & & & \\
\hline Number of doctors & 2.8 & 0.49 & $2-4$ & 2.3 & 0.50 & $2-4$ & $<0.01$ \\
\hline Operation time, $\min$ & 131.4 & 57.8 & $39-280$ & 107.2 & 47.5 & $30-336$ & $<0.01$ \\
\hline Set-up time, min & 36.8 & 7.95 & $18-70$ & 35.2 & 6.24 & $19-72$ & 0.17 \\
\hline Blood loss, ml & 71.6 & 147.2 & $5-970$ & 70.7 & 128.5 & $5-1,270$ & 0.21 \\
\hline LOHS, days & 9.4 & 4.2 & $1-42$ & 6.5 & 4.9 & $1-39$ & 0.04 \\
\hline
\end{tabular}

Set-up time $=$ Duration between room entry and skin incision; LOHS = postoperative length of hospital stay; $\mathrm{SD}=$ standard deviation.

\begin{tabular}{|c|c|c|c|c|c|c|c|}
\hline & \multicolumn{3}{|c|}{$\begin{array}{l}\text { Human assistant group } \\
(\mathrm{n}=90)\end{array}$} & \multicolumn{3}{|c|}{$\begin{array}{l}\text { Soloassist group } \\
(\mathrm{n}=135)\end{array}$} & \multirow[t]{2}{*}{$\mathrm{p}$} \\
\hline & mean & SD & range & mean & SD & range & \\
\hline Age, years & 63.7 & 12.9 & $35-92$ & 62.0 & 15.6 & $16-90$ & 0.38 \\
\hline Sex, male/female & & $43 / 47$ & & & $61 / 74$ & & 0.70 \\
\hline BMI, $\mathrm{kg} / \mathrm{m}^{2}$ & 23.7 & 3.1 & $17.9-34.0$ & 23.5 & 3.9 & $14.0-38.6$ & 0.40 \\
\hline \multicolumn{8}{|l|}{ ASA score } \\
\hline 1 & 26 & & & 39 & & & \multirow{3}{*}{0.69} \\
\hline 2 & 45 & & & 73 & & & \\
\hline 3 & 19 & & & 23 & & & \\
\hline Number of doctors & 2.9 & 0.47 & $2-4$ & 2.2 & 0.44 & $2-4$ & $<0.01$ \\
\hline Opereation time, $\min$ & 130.2 & 47.4 & $39-280$ & 92.4 & 45.0 & $30-285$ & $<0.01$ \\
\hline Set-up time, min & 38.9 & 9.20 & $18-70$ & 34.8 & 6.65 & $23-72$ & 0.07 \\
\hline Blood loss, ml & 47.3 & 154.3 & $5-970$ & 23.4 & 111.8 & $5-1270$ & 0.17 \\
\hline LOHS, days & 6.5 & 2.6 & $1-17$ & 4.6 & 2.9 & $1-25$ & $<0.01$ \\
\hline
\end{tabular}

Set-up time $=$ Duration between room entry and skin incision; LOHS = postoperative length of hospital stay; $\mathrm{SD}=$ standard deviation. significantly less in the SA group $(2.7 \pm 0.47$ vs. $2.0 \pm 0.22, \mathrm{p}<$ $0.001)$ and the operation time and postoperative length of hospital stay were also shorter $(90.2 \pm 22.2$ vs. $67.5 \pm 21.6, \mathrm{p}<0.01 ; 5.6 \pm 1.5$ vs. $3.9 \pm 1.2, p<0.001$, respectively). There was no significant difference between set-up time and amount of intraoperative blood loss.

\section{Study $1 B$}

The patients' characteristics and perioperative results of emergency laparoscopic cholecystectomy cases are shown in table 6 . Preoperative clinical information was comparable in both groups. The number of surgeons participating in surgery was significantly less in the SA group $(2.7 \pm 0.47$ vs. $2.3 \pm 0.47, \mathrm{p}=0.01)$ and the postoperative length of hospital stay was shorter $(7.1 \pm 3.1$ vs. $4.0 \pm$ $2.0, p=0.04)$. There was no significant difference in operative time and blood loss or in set-up time.
Study 2

The number of times the energy device was activated in each area and its ratio are shown in fig. 3. The total number of energy device activations decreased as the surgical resident grew accustomed to the device. Although the sample size is small and we have not accumulated a significant amount of data, procedures in the dangerous zone gradually decreased with increasing experience. In the early stages, there were quite a few energy device activations in the dangerous zone (around 20 times); however, in 4 out of the latter 5 cases, it was less than 10 times.

\section{Discussion}

For a variety of surgical interventions, laparoscopic techniques have become established as the standard procedure. Compared 
Table 4. Patients' characteristics and perioperative results in emergency cholecystectomy
Table 5. Patients' characteristics of elective laparoscopic cholecystectomy: a case-match study

\begin{tabular}{|c|c|c|c|c|c|c|c|}
\hline & \multicolumn{3}{|c|}{$\begin{array}{l}\text { Human assistant group } \\
(\mathrm{n}=44)\end{array}$} & \multicolumn{3}{|c|}{$\begin{array}{l}\text { Soloassist group } \\
(\mathrm{n}=113)\end{array}$} & \multirow[t]{2}{*}{$\mathrm{p}$} \\
\hline & mean & SD & range & mean & SD & range & \\
\hline Age, years & 64.3 & 21.8 & $27-93$ & 69.1 & 16.4 & $29-95$ & 0.13 \\
\hline Sex, male/female & $19 / 25$ & & & $64 / 49$ & & & 0.13 \\
\hline BMI, $\mathrm{kg} / \mathrm{m}^{2}$ & 24.3 & 4.8 & $15.6-34.3$ & 23.8 & 4.2 & $11.4-35.3$ & 0.50 \\
\hline \multicolumn{8}{|l|}{ ASA score } \\
\hline 1 & 3 & & & 20 & & & \multirow{4}{*}{0.45} \\
\hline 2 & 25 & & & 51 & & & \\
\hline 3 & 14 & & & 40 & & & \\
\hline 4 & 2 & & & 2 & & & \\
\hline Number of doctors & 2.8 & 0.52 & $2-4$ & 2.4 & 0.58 & $2-4$ & $<0.01$ \\
\hline Operation time, $\min$ & 152.4 & 79.8 & $43-273$ & 123.0 & 54.0 & $40-336$ & $<0.01$ \\
\hline Set-up time, min & 32.0 & 6.28 & $24-48$ & 30.2 & 5.76 & $19-49$ & 0.09 \\
\hline Blood loss, ml & 141.7 & 143.5 & $5-540$ & 82.7 & 160.7 & $5-950$ & 0.26 \\
\hline LOHS, days & 11.0 & 8.0 & $3-42$ & 9.0 & 7.1 & $1-39$ & 0.13 \\
\hline
\end{tabular}

Set-up time $=$ Duration between room entry and skin incision; LOHS = postoperative length of hospital stay; $\mathrm{SD}=$ standard deviation.

\begin{tabular}{|c|c|c|c|c|c|c|c|}
\hline & \multicolumn{3}{|c|}{ Human assistant $(\mathrm{n}=20)$} & \multicolumn{3}{|c|}{ Soloassist II $(\mathrm{n}=20)$} & \multirow[t]{2}{*}{$\mathrm{p}$} \\
\hline & mean & SD & range & mean & SD & range & \\
\hline Age, years & 64.1 & 12.8 & $38-83$ & 64.9 & 13.9 & $40-83$ & 0.85 \\
\hline Sex, male/female & $10 / 10$ & & & $10 / 10$ & & & 0.99 \\
\hline $\mathrm{BMI}, \mathrm{kg} / \mathrm{m}^{2}$ & 22.4 & 2.1 & $18.4-25.4$ & 22.79 & 1.96 & $20.1-26.4$ & 0.56 \\
\hline \multicolumn{8}{|l|}{ ASA score } \\
\hline 1 & 7 & & & 9 & & & \multirow{3}{*}{0.60} \\
\hline 2 & 11 & & & 9 & & & \\
\hline 3 & 2 & & & 2 & & & \\
\hline Number of doctors & 2.7 & 0.47 & $2-3$ & 2.0 & 0.22 & $2-3$ & $<0.01$ \\
\hline Operation duration, min & 90.2 & 22.2 & $42-132$ & 67.5 & 21.6 & $42-126$ & $<0.01$ \\
\hline Set-up time, min & 34.7 & 6.6 & $25-45$ & 34.4 & 6.7 & $23-45$ & 0.87 \\
\hline Bleeding, ml & 10.5 & 12.1 & $5-50$ & 8.5 & 11.3 & $5-50$ & 0.59 \\
\hline LOHS, days & 5.6 & 1.5 & $3-7$ & 3.9 & 1.2 & $2-6$ & $<0.01$ \\
\hline
\end{tabular}

Set-up time = Duration between room entry and skin incision; LOHS = postoperative length of hospital stay; $\mathrm{SD}=$ standard deviation. with conventional open surgery, laparoscopic surgery has proved its superiority in various prospective randomized comparison studies [18-20]. With advances in the equipment used for laparoscopic surgery, the progress of imaging typified by full high-vision images, $3 \mathrm{D}$, and $4 \mathrm{~K}$ has contributed to a very safe and precise procedure [21]. In order to maximize the advanced image quality, stable camera operation without trembling is desirable.

Although passive scope holders initially provided a stable operative field by fixing the laparoscope $[22,23]$, the operator had to interrupt the procedure to move it. Therefore, new products that facilitate single-handed repositioning were developed [12, 13]. Recently, robotic scope holders have been developed that allow the operator to control the scope without removing their hands from the forceps, e.g. the AESOP ${ }^{\circledR}$ robot (Automated Endoscopic System for Optimal Positioning robot; Computer Motion, Sunnyvale, CA, USA) [14], EndoAssist ${ }^{\circledR}$ (Armstrong Healthcare Ltd, High
Wycombe, UK) [15], ViKY ${ }^{\circledR}$ (EndoControl, Grenoble, France) [16], and Soloassist [17]. They react to the voice, to head motion signals, or to a joystick positioned on the left-hand side of the instrument. Merola et al. [24] reported that there was less smudging, fogging, and inadvertent movements of the laparoscope when it was controlled by a robotic system. Also, Takahashi et al. [16] examined 25 cases of laparoscopic inguinal hernia repair with ViKY and reported its benefits.

The scope holder system provides a stable operative field without tiring the assistant's arm, even in extreme endoscope positions for as long as required, which is a considerable advantage over manual camera control by a human assistant. However, prior active camera holders require large parts for scope holding or a large thick circular frame in the surgical field, which are structurally necessary to control the scope movement [16]. As a result, they cause some interference with the forceps and restrict the motion of the 
Table 6. Patients' characteristics of emergency laparoscopic cholecystectomy: a case-match study

\begin{tabular}{|c|c|c|c|c|c|c|c|}
\hline & \multicolumn{3}{|c|}{ Human assistant $(\mathrm{n}=20)$} & \multicolumn{3}{|c|}{ Soloassist II $(\mathrm{n}=20)$} & \multirow[t]{2}{*}{$\mathrm{p}$} \\
\hline & mean & SD & range & mean & SD & range & \\
\hline Age & 58.9 & 21.1 & $27-93$ & 60.2 & 18.3 & $29-90$ & 0.85 \\
\hline Sex, male/female & $9 / 11$ & & & $8 / 12$ & & & 0.76 \\
\hline BMI, $\mathrm{kg} / \mathrm{m}^{2}$ & 22.4 & 4.9 & $15.6-33.8$ & 23.3 & 3.4 & $17.5-29.8$ & 0.44 \\
\hline \multicolumn{8}{|l|}{ ASA score } \\
\hline 1 & 6 & & & 7 & & & \\
\hline 2 & 8 & & & 8 & & & \multirow{2}{*}{0.70} \\
\hline 3 & 6 & & & 5 & & & \\
\hline Number of doctors & 2.7 & 0.47 & $2-3$ & 2.3 & 0.47 & $2-3$ & 0.01 \\
\hline Operation duration, min & 113.4 & 43.8 & $45-219$ & 94.8 & 34.2 & $41-160$ & 0.14 \\
\hline Set-up time, min & 38.3 & 6.19 & $24-45$ & 34.4 & 5.84 & $20-46$ & 0.36 \\
\hline Bleeding, ml & 35.8 & 77.0 & $5-250$ & 52.8 & 21.7 & $5-400$ & 0.54 \\
\hline LOHS, days & 7.1 & 3.1 & $3-14$ & 4.0 & 2.0 & $2-11$ & 0.04 \\
\hline
\end{tabular}

Set-up time $=$ Duration between room entry to skin incision; LOHS $=$ postoperative length of hospital stay. camera itself. Other types of active scope holders which must be installed on the floor occupy precious space near the operating table [15]. The simply designed holder arm and universal joint of Soloassist decrease interference with the forceps and enables unhindered access to the patient site, no bothersome components impeding the trocar area. Moreover, because it is attached to the operating table, it does not affect the location of the energy supplier, the trolley of laparoscopic equipment, and the anesthetic device. What is more, readjustment is not necessary in accordance with tilting of the operating table which is indispensable for laparoscopic colorectal surgery. Due to the limitations of its performance, surgery employing such a new device sometimes cannot be completed in all cases, and thus it becomes necessary to change it over to the human assistant. In our experience of 949 procedures with Soloassist, however, it could be applied to various surgical procedures, and there was no conversion case to human assistant or device-related complication.

As an experimental study, we compared the results of the perioperative period in the cholecystectomy cases before and after introducing Soloassist. In elective cases, operation time and length of hospital stay were significantly shorter in the SA group. In addition, in emergency cases, the SA group had a shorter hospital stay and no adverse results were observed. In our institution, trainees with little experience are often in charge of the camera assistants in elective operation; therefore, the use of Soloassist, which can be controlled by the operator, contributed to a shortening of the operation time. Although not examined for all cases, we counted the amount of scope cleaning due to intraoperative contamination in 10 cases each in both the HA group and the SA group, and the average numbers were 3.2 in the HA group and 0.9 in the SA group. Therefore, the time required for scope cleaning and unnecessary scope movement causing contamination could also affect the difference in operation time. In recently reported robotic surgery, it takes a longer time to set up due to the size of the device, and the room occupying time is lengthened for each individual operation [25]. According to the results of our study, the set-up time of the SA group was almost similar to that of the HA group. The Soloas-

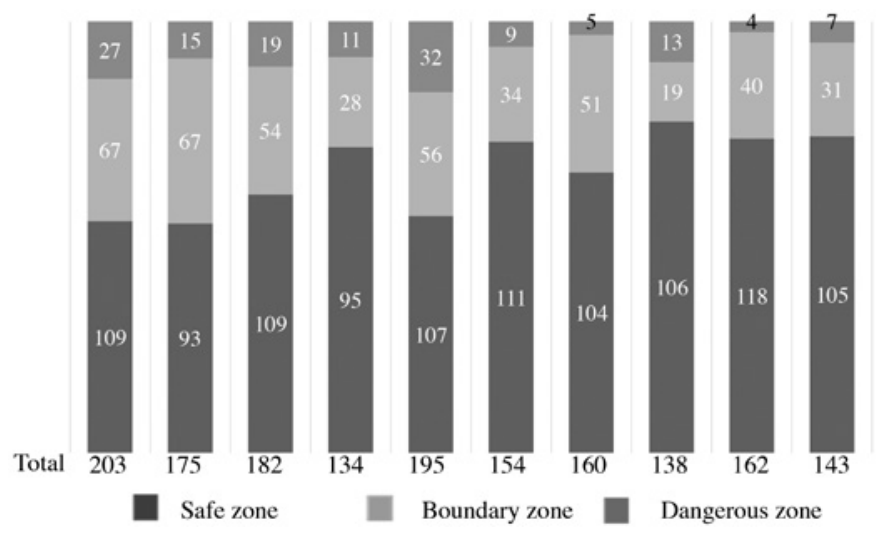

Fig. 3. Ratio of the location where the energy device was activated in laparoscopic cholecystectomy by a single surgical resident.

sist can be easily attached to the operation table; thus, the set-up time was completely included in the preoperative preparation time in both elective and emergency cases.

The number of surgeons was statistically smaller in the SA group compared to the HA group both in elective and emergency cases. The most serious shortcoming of emergency surgery is the potential for time lags between an arising emergency and its surgical control, which can be delayed due to the late arrival of surgical personnel. Scope holders can solve this problem and help in economizing staff, thus contributing to a reduction of personnel costs. In Japan, and also in other countries, some concerns have been raised regarding an apparent shortage of general surgeons, and a decline in residency applications to surgical departments has caused manpower shortages [26-29]. Under these circumstances, scope holders pave the way for accommodating a higher amount of operations with limited manpower.

We devised a unique model as a method to evaluate the degree of achievement of Soloassist usage. Interestingly, as the number of experienced cases increased, procedures in the dangerous zone gradually decreased; $70 \%$ of the energy device activation was performed in the safe zone, while that in the dangerous zone was less 
than $10 \%$. Based on our results, 5 consecutive experiences are necessary before a proficient use of the joystick can be achieved. Aiono et al. [15] randomized 93 cholecystectomy patients, i.e. 40 for active scope holder (EndoAssist) and 46 for human assistant, excluding 7 converted cases, and reported favorable results in the active scope holder group; the surgeons became competent within 3 cases.

Some are of the opinion that experience as a scope assistant is also necessary for laparoscopic surgical training. However, unlike other active scope holders, Soloassist can solve this matter because it is possible for trainees to secure an appropriate field of view by operating the joystick as a scope assistant at a remote location. Also, it is a great advantage that the assistant's shoulders and arms are not in the vicinity of the surgeon during the operation, providing a highly flexible and relaxed working environment.

Although robotic surgery has attracted attention owing to its restoration of the eye-hand-target axis, three-dimensional (3D) imaging, and extra degrees of freedom for the instruments, there are various problems that are widely accepted based on scientific evidence. In previous studies analyzing a large-scale clinical database, a clinical benefit cannot be confirmed with robot-assisted colorectal resection, and it is reported that robotic surgery comes along with significantly higher costs compared to laparoscopic surgery [9-11]. Moreover, in the ROLARR (RObotic Versus LAparoscopic Resection for Rectal Cancer) trial, which attracted attention as a high-quality multicenter prospective randomized controlled trial comparing robotic rectal resection for rectal cancer with laparoscopic resection, there was no statistically significant difference regarding conversion rate to open surgery, configured as a primary endpoint, as well as in bladder dysfunction, sexual function, and pathological resection margin positivity [30].

According to the report that evaluated to which extent two-dimensional (2D), 3D and robotic surgery can result in advantages for the surgical technique depending on the skill level of the surgeon, the obvious benefits of robotic surgery were demonstrated only in novices. The intermediate group completed the task equally well and quickly with 3D laparoscopy and by robotic surgery. The experts completed the task equally well regardless of the instrument; however, they were much faster with 3D laparoscopy than with $2 \mathrm{D}$ and robotic surgery. Thus, well-trained laparoscopic surgeons may not really benefit from 3D robot systems if 3D laparoscopy is available [31].

Considering all the results, robotic surgery should only be performed for limited surgery, such as prostatectomy, with complex procedures in limited workspaces. Even though robotic surgery is slightly superior to conventional laparoscopic surgery, this does not seem to be enough to obtain better clinical benefits compared to recently released high-priced drugs including immunotherapy [32], because they require exactly the same surgical wound. Surgical oncologists of the present era, including us, should perform robotic surgery in limited procedures not as a surgeon but as a clinical oncologist. A robotic scope holder can reduce manpower and can be universally used both in elective surgery and emergency surgery. Development of robotic technology is also necessary for the future development of surgery; however, it is necessary to take the most desirable cost benefit into consideration for patients who are struggling with diseases under limited medical expenses. Naturally, as a surgeon, robotic surgery is very interesting and there is a desire to perform it as a surgeon, but to make it universally applicable to various diseases would require immense financial resources, manpower, and a new educational system.

In conclusion, Soloassist was useful in both elective and emergency cholecystectomy cases, contributing to a shortened operation time and a decrease in participating surgeons, while there was no additional time required for its setup. Approximately 5 cases of experience were considered necessary to get used to Soloassist. Considering our results and previous reports, the combination use of an ideal active scope holder and a commercially available 3D scope is currently considered the best approach in laparoscopic surgery. From such a perspective, the development of active scope holders might play an important role in laparoscopic surgery in the near future.

\section{Disclosure Statement}

Drs. Yasushi Ohmura, Mari Nakagawa, Hiromitsu Suzuki, Kazutoshi Kotani, and Atsushi Teramoto have no conflicts of interest or financial ties to disclose.

\section{References}

1 Semm K: Endoscopic appendectomy. Endoscopy 1983; 15:59-64.

2 Litynski GS: Erich Mühe and the rejection of laparoscopic cholecystectomy (1985): a surgeon ahead of his time. JSLS 1998;2:341-346.

3 Jacobs M, Verdeja JC, Goldstein HS: Minimally invasive colon resection (laparoscopic colectomy). Surg Laparosc Endosc 1991;1:144-150.

4 Cuschieri A: Endoscopic subtotal oesophagectomy for cancer using the right thoracoscopic approach. Surg Oncol 1993;2(suppl 1):3-11.

5 Kitano S, Iso Y, Moriyama M, Sugimachi K: Laparoscopy-assisted Billroth I gastrectomy. Surg Laparosc Endosc 1994;4:146-148.
6 Bann S, Khan M, Hernandez J, Munz Y, Moorthy K, Datta V, Rockall T, Darzi A: Robotics in surgery. J Am Coll Surg 2003;196:784-795.

7 Yang SY, Roh KH, Kim YN, Cho M, Lim SH, Son T, Hyung WJ, Kim HI: Surgical outcomes after open, laparoscopic, and robotic gastrectomy for gastric cancer. Ann Surg Oncol 2017;24:1770-1777.

$8 \mathrm{Kim} \mathrm{CW}$, Kim CH, Baik SH: Outcomes of robotic-assisted colorectal surgery compared with laparoscopic and open surgery: a systematic review. J Gastrointest Surg 2014;18:816-830.

9 Keller DS, Senagore AJ, Lawrence JK, Champagne BJ, Delaney CP: Comparative effectiveness of laparoscopic versus robot-assisted colorectal resection. Surg Endosc 2014;28:212-221
10 Yeo HL, Isaacs AJ, Abelson JS, Milsom JW, Sedrakyan A: Comparison of open, laparoscopic, and robotic colectomies using a large national database: outcomes and trends related to surgery center volume. Dis Colon Rectum 2016;59:535-542.

11 Tyler JA, Fox JP, Desai MM, Perry WB, Glasgow SC: Outcomes and costs associated with robotic colectomy in the minimally invasive era. Dis Colon Rectum 2013; 56:458-466.

12 Arezzo A, Schurr MO, Braun A, Buess GF: Experimental assessment of a new mechanical endoscopic solosurgery system: Endofreeze. Surg Endosc 2005; 19: 581-588. 
13 Lee YS, Jeon HG, Lee SR, Jeong WJ, Yang SC, Han WK: The feasibility of solo-surgeon living donor nephrectomy. Surg Endosc 2010;24:2755-2759.

14 Yavuz Y, Ystgaard B, Skogvoll E, Mårvik R: A comparative experimental study evaluating the performance of surgical robots aesop and endosista. Surg Laparosc Endosc Percutan Tech 2000;10:163-167.

15 Aiono S, Gilbert JM, Soin B, Finlay PA, Gordan A: Controlled trial of the introduction of a robotic camera assistant (EndoAssist) for laparoscopic cholecystectomy. Surg Endosc 2002;16:1267-1270.

16 Takahashi M, Takahashi M, Nishinari N, Matsuya H, Tosha T, Minagawa Y, Shimooki O, Abe T: Clinical evaluation of complete solo surgery with the ' $\mathrm{ViKY}{ }^{\circledR}$, robotic laparoscope manipulator. Surg Endosc 2017; 31:981-986.

17 Gillen S, Pletzer B, Heiligensetzer A, Wolf P, Kleeff J, Feussner H, Fürst A: Solo-surgical laparoscopic cholecystectomy with a joystick-guided camera device: a case-control study. Surg Endosc 2014;28:164-170.

18 Clinical Outcomes of Surgical Therapy Study Group Nelson H, Sargent DJ, Wieand HS, Fleshman J, Anvari M, Stryker SJ, Beart RW Jr, Hellinger M, Flanagan R Jr, Peters W, Ota D: A comparison of laparoscopically assisted and open colectomy for colon cancer. N Engl J Med 2004;350:2050-2059.

19 Colon Cancer Laparoscopic or Open Resection Study Group; Buunen M, Veldkamp R, Hop WC, Kuhry E, Jeekel J, Haglind E, Påhlman L, Cuesta MA, Msika S, Morino M, Lacy A, Bonjer HJ: Survival after laparoscopic surgery versus open surgery for colon cancer: long-term outcome of a randomised clinical trial. Lancet Oncol 2009;10:44-52.
20 Hu Y, Huang C, Sun Y, Su X, Cao H, Hu J, Xue Y, Suo J, Tao K, He X, Wei H, Ying M, Hu W, Du X, Chen P, Liu H, Zheng C, Liu F, Yu J, Li Z, Zhao G, Chen X, Wang K, Li P, Xing J, Li G: Morbidity and mortality of laparoscopic versus open D2 distal gastrectomy for advanced gastric cancer: a randomized controlled trial. J Clin Oncol 2016;34:1350-1357.

21 Sakata S, Grove PM, Hill A, Watson MO, Stevenson ARL: Impact of simulated three-dimensional perception on precision of depth judgements, technical performance and perceived workload in laparoscopy. $\mathrm{Br} \mathrm{J}$ Surg 2017;104:1097-1106.

22 Arezzo A, Ulmer F, Weiss O, Schurr MO, Hamad M, Buess GF: Experimental trial on solo surgery for minimally invasive therapy: comparison of different systems in a phantom model. Surg Endosc 2000;14:955959.

23 Schurr MO, Buess G, Schwarz K: Robotics in endoscopic surgery: can mechanical manipulators provide a more simple solution for the problem of limited degrees of freedom? Minim Invasive Ther Allied Technol 2001;10:289-293.

24 Merola S, Weber P, Wasielewski A, Ballantyne GH: Comparison of laparoscopic colectomy with and without the aid of a robotic camera holder. Surg Laparosc Endosc Percutan Tech 2002;12:46-51.

25 Ruurda JP, Visser PL, Broeders IA: Analysis of procedure time in robot-assisted surgery: comparative study in laparoscopic cholecystectomy. Comput Aided Surg 2003;8:24-29.

26 Mizuno Y, Narimatsu H, Kodama Y, Matsumura T, Kami M: Mid-career changes in the occupation or specialty among general surgeons, from youth to middle age, have accelerated the shortage of general surgeons in Japan. Surg Today 2014;44:601-606.
27 Chen YC, Shih CL, Wu CH, Chiu CH: Exploring factors that have caused a decrease in surgical manpower in Taiwan. Surg Innov 2014;21:520-527.

28 Deedar-Ali-Khawaja R, Khan SM: Trends of surgical career selection among medical students and graduates: a global perspective: J Surg Educ 2010;67:237248.

29 Marschall JG, Karimuddin AA: Decline in popularity of general surgery as a career choice in North America: review of postgraduate residency training selection in Canada, 1996-2001. World J Surg 2003;27:249-252.

30 Jayne D, Pigazzi A, Marshall H, Croft J, Corrigan N, Copeland J, Quirke P, West N, Rautio T, Thomassen N, Tilney H, Gudgeon M, Bianchi PP, Edlin R, Hulme C, Brown J: Effect of robotic-assisted vs conventional laparoscopic surgery on risk of conversion to open laparotomy among patients undergoing resection for rectal cancer: the ROLARR randomized clinical trial. JAMA 2017;318:1569-1580.

31 Park YS, Oo AM, Son SY, Shin DJ, Jung DH, Ahn SH, Park DJ, Kim HH: Is a robotic system really better than the three-dimensional laparoscopic system in terms of suturing performance?: comparison among operators with different levels of experience. Surg Endosc 2016; 30:1485-1490.

32 Kang YK, Boku N, Satoh T, et al: Nivolumab in patients with advanced gastric or gastro-oesophageal junction cancer refractory to, or intolerant of, at least two previous chemotherapy regimens (ONO-4538-12, ATTRACTION-2): a randomized, double-blind, placebo-controlled, phase 3 trial. Lancet 2017;390:24612471 . 